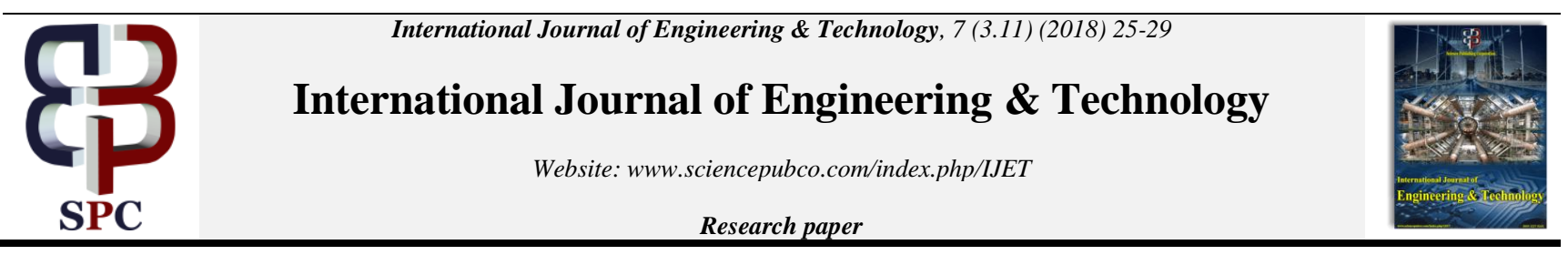

\title{
The Effect of Channel Length on Phase Transition of Phase Change Memory
}

\author{
M.S. A.Aziz ${ }^{1 *}$, F.H. M.Fauzi ${ }^{2}$, Z. Mohamad, R.I. Alip \\ ${ }^{1}$ Universiti Teknologi MARA Shah Alam, Selangor. Malaysia \\ ${ }^{2}$ Politeknik Ungku Omar Ipoh, Perak Malaysia \\ *Corresponding author E-mail: sharimanfarahuwais1@gmail.com
}

\begin{abstract}
The phase transition of germanium antimony tellurium (GST) and the temperature of GST were investigated using COMSOL Multiphysic 5.0 software. Silicon carbide was using as a heater layer in the separate heater structure of PCM. These simulations have a different channel of SiC. The temperature of GST and the phase transition of GST can be obtained from the simulation. From the simulation, the $300 \mathrm{~nm}$ channel of $\mathrm{SiC}$ can change the GST from amorphous to crystalline state at $0.7 \mathrm{~V}$ with $100 \mathrm{~ns}$ pulse width. The $800 \mathrm{~nm}$ channel of $\mathrm{SiC}$ can change the GST from amorphous to crystalline state at $1.1 \mathrm{~V}$ with $100 \mathrm{~ns}$ pulse width. Results demonstrated that the channel of SIC can affecting the temperature of GST and the GST changes from amorphous state to crystalline state. As the channel of SiC decreased, the temperature of GST was increased and the GST was change to crystalline state quickly.
\end{abstract}

Keywords: Phase change memory; Separate heater structure; Silicon carbide; Channel of SiC; Heater layer.

\section{Introduction}

A non-volatile memory (NVM) is one of the technologies that plays an important role in the semiconductor market. Phase change memory (PCM) is a one of the non-volatile memory. The history of phase change memory has begun when these device were first proposed by S.Ovshinsky in late 1960s [1]. Phase change memory has a unique behavior of phase change material that can change from amorphous to crystalline using application of heat. The change from amorphous to crystalline enable data to be stored and the change from crystalline to amorphous allow data to be deleted. The research of PCM is enhanced over the decades due to high endurance, low programmable energy, fast switching speed, good data retention and excellent scalability [2], [3] [4].

PCM is based on repeated switching of phase change material between crystalline and amorphous state. Many types of phase change material used in semiconductor industry such as GeTe, GST, SbTe and many chalcogenide glass [5], [6]. Germaniumantimony-tellurium, $\mathrm{Ge}_{2} \mathrm{Sb}_{2} \mathrm{Te}_{5}$ (GST) is a chalcogenide glass which is widely used in phase change memory industry [7]. High resistive and short-range atomic order are the characteristic of GST in amorphous state. However, when the GST in crystalline state, it has a low resistivity and long range atomic order. The GST has a very high crystallization rate and very good reversibility between amorphous and crystalline phases [8]. The additional of Ge in GST can produce GST that has high thermal stability. The crystalline temperature of GST is $450 \mathrm{~K}$ and the melting temperature of GST is $900 \mathrm{~K}$.

The heater layer that used in this work is silicon carbide ( $\mathrm{SiC})$ because this semiconductor can operate at the high temperature, high power, excellent shock resistance, low thermal expansion and the resistance of $\mathrm{SiC}$ did not change significantly at higher temperature [9], [10], [11]. The COMSOL Multiphysic 5.0 software was used for simulating the separate heater structure of PCM that consist the memory layer, insulator layer, heater layer, 4 electrodes and capping layer [4], [5]. A. Lacita et al. (2006) proposed the PCM with 50ns-100ns but memory layer was heated directly by heater [8] whereas the Irma R, Kobayashi R, Zhang YL et al (2013) proposed the phase change memory structure with separate heater using Titanium Sitride (TiSi3) as a heater layer [4], [5].

\section{Experimental}

In this work, the separate heater structure of PCM was used to obtain the temperature of GST and phase transition of GST. The advantage of this structure is the power can be controlled depend on the voltage pulse. This structure was simulated by using a COMSOL Multiphysic 5.0 software. The COMSOL Multiphysics 5.0 software has been used for finite element analysis, solver and simulation software for various physic and engineering applications. The figure 1 shows the material and the thickness of material that used in this simulation. 


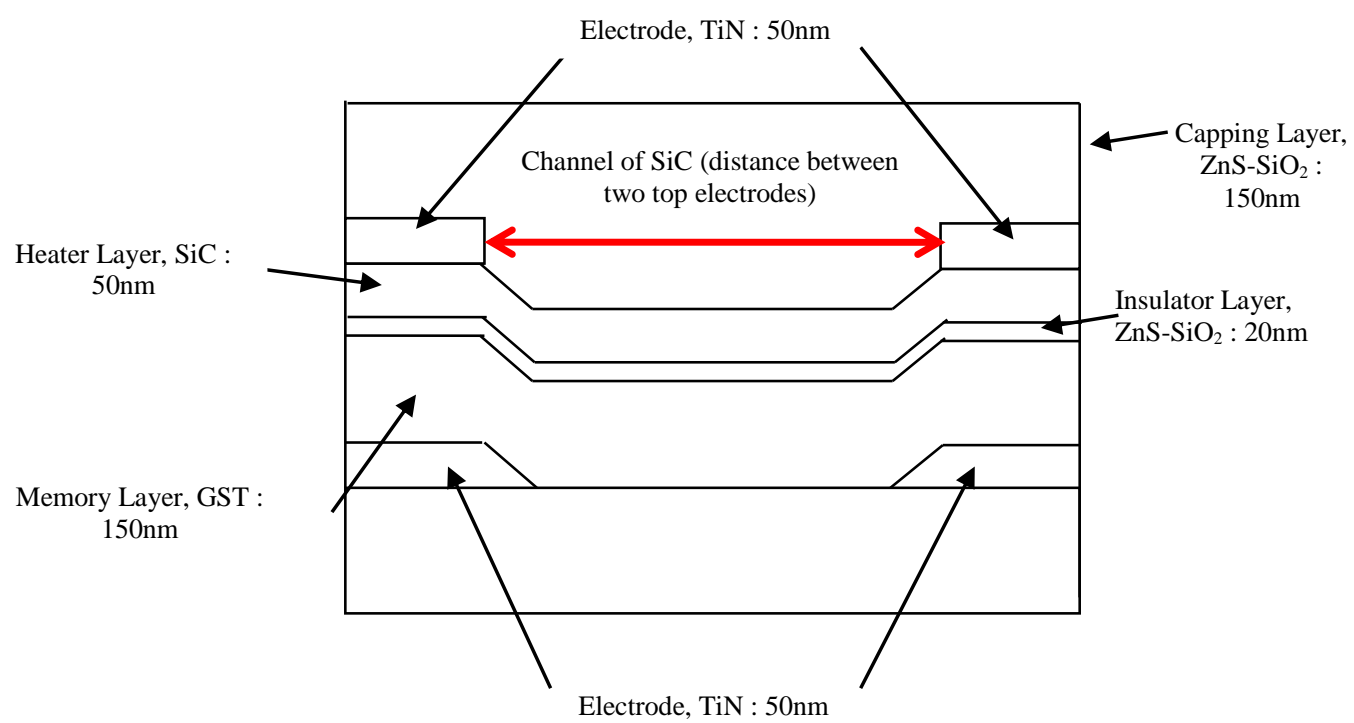

Fig. 1: The thickness for all material and the different channel of SiC that used in this simulation.

\begin{tabular}{|c|c|c|c|c|}
\hline Material & Heat capacity (J/kg.K) & Thermal conductivity (W/m.K) & Density $\left(\mathrm{kg} / \mathrm{m}^{3}\right)$ & Electrical conductivity $(\mathrm{S} / \mathrm{m})$ \\
\hline Capping Layer,ZnS-SiO & 263 & 0.657 & 3650 & 0.02 \\
\hline Insulator Layer, ${\mathrm{ZnS}-\mathrm{SiO}_{2}}_{2}$ & 263 & 0.657 & 3650 & 0.02 \\
\hline Electrode, TiN & 784 & 22 & 5240 & $5.0 \times 10^{6}$ \\
\hline Heater, SiC & 670 & 120 & 3200 & $4.3 \times 10^{4}$ \\
\hline Memory layer, a-GST & 202 & 0.46 & 6200 & $3.6 \times 10^{-1}$ \\
\hline Memory Layer, c-GST & 202 & 0.46 & 6200 & $2.0 \times 10^{2}$ \\
\hline
\end{tabular}

In this work, the simulation with different channel of $\mathrm{SiC}$ was simulated to determine the temperature of GST and the phase transition of GST. There are six differences thickness of channel of $\mathrm{SiC} ; 300 \mathrm{~nm}, 400 \mathrm{~nm}, 500 \mathrm{~nm}, 600 \mathrm{~nm}, 700 \mathrm{~nm}$ and $800 \mathrm{~nm}$ were applied. Channel of $\mathrm{SiC}$ is a distance between the two top electrodes as can be seen at the Figure 1. The physical properties of material that used in this simulation can be seen on the table 1 . The applied voltage with $100 \mathrm{~ns}$ pulse width was used at the two top electrodes. This voltage pulse heated up the heater layer and $\mathrm{SiC}$ material. The function of insulator layer is to ensure the heater layer not connected electrically to the memory layer, GST and the teat transfer occurred which cause the temperature of GST to increase. On the other hand, the temperature of GST and the phase transition of GST determined for every voltage that has been applied at the two top electrodes.

\section{Result and Discussion}

Table 2 shows the temperature of GST when using the different channel of SiC. The result of the simulation revealed that the different of channel of $\mathrm{SiC}$ could affect the temperature of GST, which the decreasing channel of $\mathrm{SiC}$ caused the temperature of GST increased. It is observed that the temperature of GST at $0.7 \mathrm{~V}$ with $100 \mathrm{~ns}$ pulse width is $468.39 \mathrm{~K}$ when the channel of $\mathrm{SiC}$ is $300 \mathrm{~nm}$ meanwhile the temperature of GST at $1.1 \mathrm{~V}$ with $100 \mathrm{~ns}$ pulse width is $468.22 \mathrm{~K}$ when the channel of $\mathrm{SiC}$ is $800 \mathrm{~nm}$. Furthermore, the red color of temperature indicates that the GST already change from amorphous state to crystalline state. The WRITE process can be done and data can be stored. The figure 2 shows the temperature of GST with different channel of SiC.

Table 2: The temperature of GST when using the different channel of SiC.

\begin{tabular}{|c|c|c|c|c|c|c|}
\hline \multirow{2}{*}{$\begin{array}{c}\text { Ap- } \\
\text { plied } \\
\text { Volt- } \\
\text { age (V) }\end{array}$} & \multicolumn{6}{|c|}{ Temperature (K) } \\
\hline & $\begin{array}{c}\text { 300nm channel of } \\
\mathrm{SiC}\end{array}$ & $\begin{array}{c}\text { 400nm channel of } \\
\mathrm{SiC}\end{array}$ & $\begin{array}{c}500 \mathrm{~nm} \text { channel of } \\
\mathrm{SiC}\end{array}$ & $\begin{array}{c}\text { 600 } \mathrm{nm} \text { channel of } \\
\mathrm{SiC}\end{array}$ & $\begin{array}{c}\text { 700nm channel of } \\
\mathrm{SiC}\end{array}$ & $\begin{array}{c}800 \mathrm{~nm} \text { channel of } \\
\mathrm{SiC}\end{array}$ \\
\hline 0.5 & 396.4 & 376.95 & 363.34 & 356.06 & 345.23 & 338.58 \\
\hline 0.6 & 436.05 & 410.57 & 391.71 & 381.62 & 366.78 & 357.01 \\
\hline 0.7 & 468.39 & 443.99 & 423.71 & 410.59 & 391.19 & 379.06 \\
\hline 0.8 & 503.01 & 469.22 & 450.33 & 440.02 & 417.4 & 402.11 \\
\hline 0.9 & 544.65 & 502.95 & 472.58 & 465.11 & 444.25 & 427.86 \\
\hline 1 & 589.74 & 542.22 & 508.71 & 491.17 & 465.54 & 449.25 \\
\hline 1.1 & 634.3 & 581.64 & 539.61 & 521.01 & 487.3 & 468.22 \\
\hline 1.2 & 682 & 622.43 & 579.66 & 554.84 & 517.46 & 493.15 \\
\hline 1.3 & 736.17 & 667.66 & 615.28 & 589.29 & 544.26 & 517.54 \\
\hline 1.4 & 785.94 & 710.65 & 655.58 & 624.15 & 576.54 & 543.21 \\
\hline 1.5 & 843.94 & 758.54 & 697.5 & 661.53 & 604.98 & 570.87 \\
\hline 1.6 & 899.03 & 804.7 & 737.02 & 700.55 & 637.47 & 603.33 \\
\hline 1.7 & 960.87 & 848.07 & 774.82 & 739.31 & 675.43 & 633.58 \\
\hline 1.8 & & 903.5 & 818.17 & 779.43 & 717.15 & 663.37 \\
\hline 1.9 & & & 860.87 & 822.55 & 743.02 & 699.51 \\
\hline 2 & & & 911.39 & 858.61 & 778.47 & 731.43 \\
\hline 2.1 & & & & 904.46 & 816.18 & 765.65 \\
\hline 2.2 & & & & 947.66 & 853.05 & 795.51 \\
\hline 2.3 & & & & & 897.54 & 834.57 \\
\hline
\end{tabular}




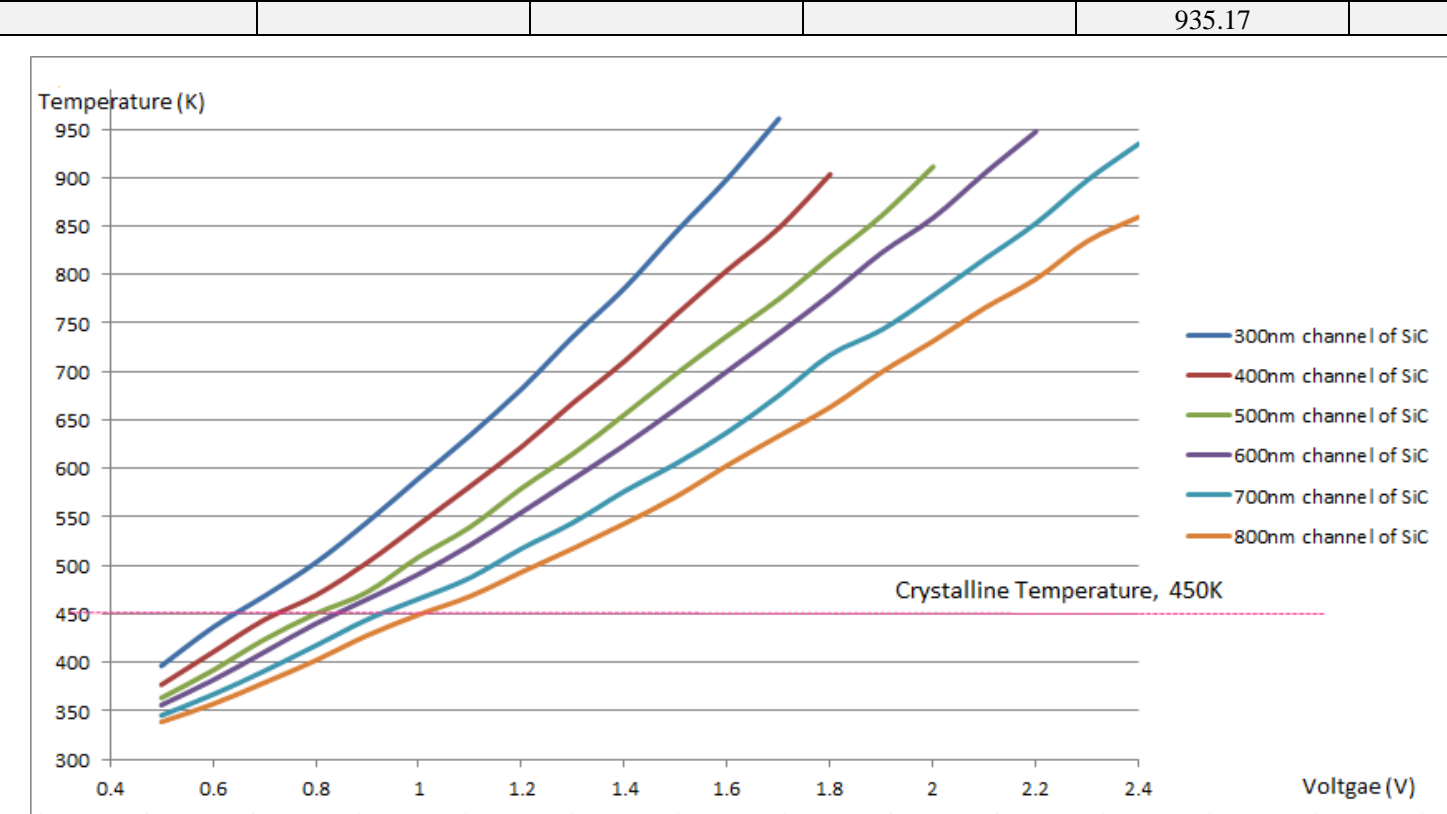

Fig. 2: The temperature of GST with different channel of SiC.

The table 3 shows the percentage of phase transition of GST for different channel of SiC. As can be seen, the applied voltage that changes the GST to crystalline state became increased when the channel of SiC decreased. Comparison between the results are when using the $300 \mathrm{~nm}$ channel of $\mathrm{SiC}$, the applied voltage is $0.7 \mathrm{~V}$ with $100 \mathrm{~ns}$ pulse width and when using the $800 \mathrm{~nm}$ channel of $\mathrm{SiC}$, the applied voltage is $1.1 \mathrm{~V}$ with $100 \mathrm{~ns}$ pulse width. Therefore, the closer distance between the two top electrodes can make the GST changed to crystalline state quickly. The red color percentage represent the phase transition of GST whether the GST changes to crystalline state completely or not.

Table 3: The phase transition of GST for different channel of SiC.

\begin{tabular}{|c|c|c|c|c|c|c|}
\hline & \multicolumn{6}{|c|}{ Percentage of phase transition of GST for different channel of SiC } \\
\hline $\begin{array}{c}\text { Applied Voltage } \\
\text { (V) }\end{array}$ & $\begin{array}{c}\text { 300nm channel of } \\
\text { SiC }\end{array}$ & $\begin{array}{c}\text { 400nm channel of } \\
\mathrm{SiC}\end{array}$ & $\begin{array}{c}\text { 500nm channel of } \\
\text { SiC }\end{array}$ & $\begin{array}{c}\text { 600nm channel of } \\
\mathrm{SiC}\end{array}$ & $\begin{array}{c}\text { 700nm channel of } \\
\text { SiC }\end{array}$ & $\begin{array}{c}\text { 800nm channel of } \\
\text { SiC }\end{array}$ \\
\hline 0.6 & $12 \%$ & $0 \%$ & $0 \%$ & $0 \%$ & $0 \%$ & $0 \%$ \\
\hline 0.7 & $100 \%$ & $32 \%$ & $0 \%$ & $0 \%$ & $0 \%$ & $0 \%$ \\
\hline 0.8 & $100 \%$ & $100 \%$ & $60 \%$ & $18 \%$ & $0 \%$ & $0 \%$ \\
\hline 0.9 & $100 \%$ & $100 \%$ & $100 \%$ & $95 \%$ & $31 \%$ & $0 \%$ \\
\hline 1.0 & $100 \%$ & $100 \%$ & $100 \%$ & $100 \%$ & $98 \%$ & $52 \%$ \\
\hline 1.1 & $100 \%$ & $100 \%$ & $100 \%$ & $100 \%$ & $100 \%$ & $100 \%$ \\
\hline 1.2 & $100 \%$ & $100 \%$ & $100 \%$ & $100 \%$ & $100 \%$ & $100 \%$ \\
\hline
\end{tabular}

The figure 3 shows the phase transition of GST when the applied voltage is $0.6 \mathrm{~V}$ and $0.7 \mathrm{~V}$ with $100 \mathrm{~ns}$ pulse width for $300 \mathrm{~nm}$ channel of SiC. Figure 3 shows the phase transition of GST when the applied voltage is $1.0 \mathrm{~V}$ and $1.1 \mathrm{~V}$ with $100 \mathrm{~ns}$ pulse width for

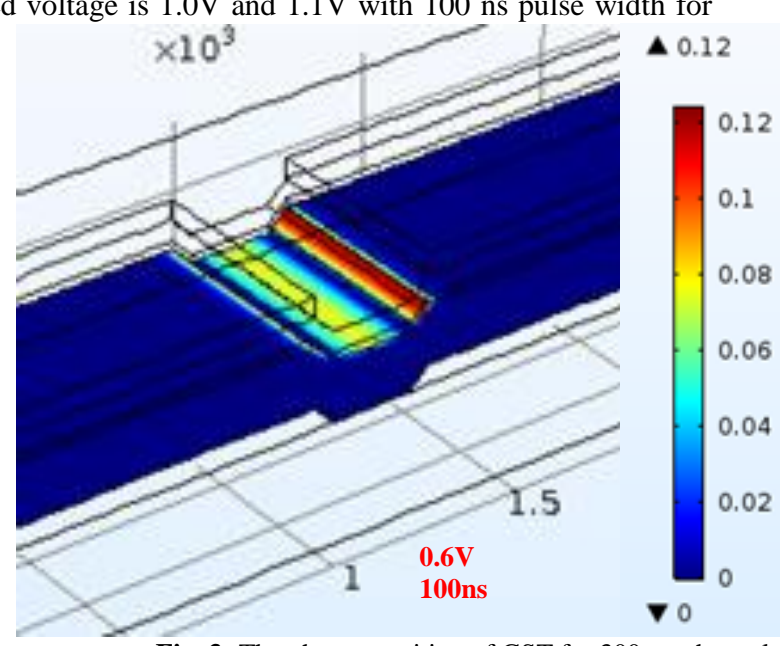

Fig. 3: The phase transition of GST for $300 \mathrm{~nm}$ channel of $\mathrm{SiC}$ at $0.6 \mathrm{~V}$ and $0.7 \mathrm{~V}$ with $100 \mathrm{~ns}$ pulse width.
$800 \mathrm{~nm}$ channel of $\mathrm{SiC}$. The red area at the Figure 3 and 4 show that the GST changes to crystalline state and blue area shows that the GST still in amorphous state.

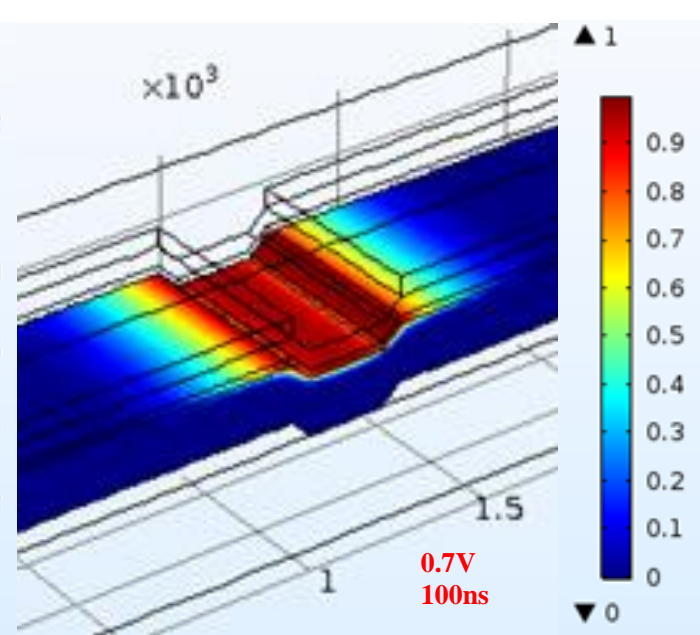




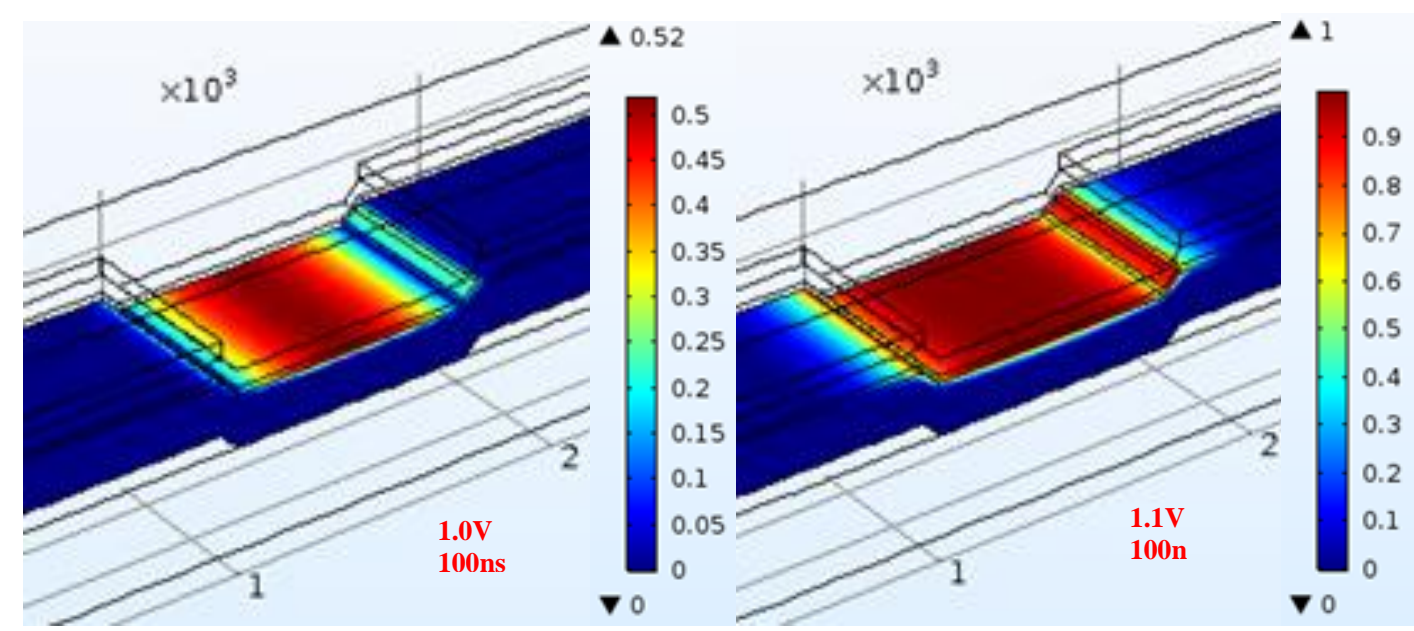

Fig. 4: The phase transition of GST for $800 \mathrm{~nm}$ channel of SiC at $1.0 \mathrm{~V}$ and $1.1 \mathrm{~V}$ with $100 \mathrm{~ns}$ pulse width.

From the figure 5 , the ability of current to flow between the two top electrodes must be considered in this situation. If the two top electrodes are close, the ability of current to flow is very easy when the applied voltage was applied at the two top electrodes. When the current is flowing through the two top electrodes, it would heat up the $\mathrm{SiC}$. As the temperature of $\mathrm{SiC}$ increase the joule heating process occur. The GST would be heated by the heater layer $(\mathrm{SiC})$. If the channel of $\mathrm{SiC}$ is slightly far, the ability of current to flow is very hard. It takes a time to heat up the heater (SiC) and also the GST too. The GST could change from amorphous state to crystalline state with an application of heat. This explain the channel of $\mathrm{SiC}$ is closely related to the ability of current to flow through the two top electrodes in this simulation.

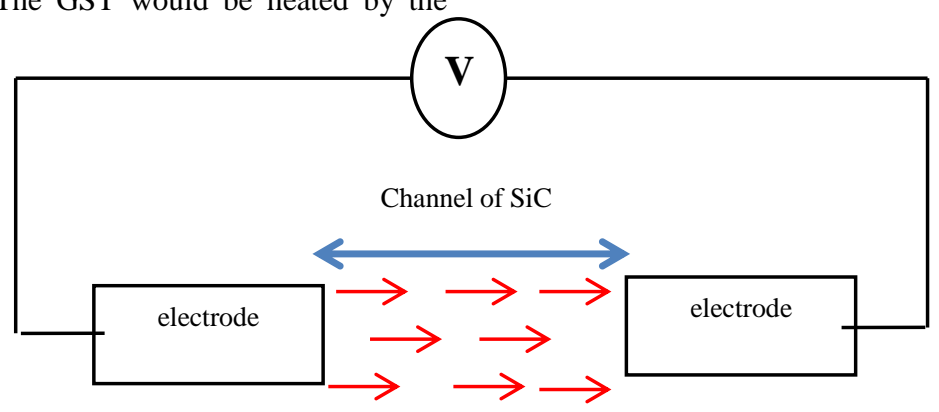

Current flow through the two top electrodes in PCM's structure

Fig. 5: The flow of current through the two top electrodes.

\section{Conclusion}

The simulations of separate heater structure of PCM with different channel of $\mathrm{SiC}$ were successfully simulated using the COMSOL Multiphysic 5.0 software. The $300 \mathrm{~nm}$ channel of $\mathrm{SiC}$ can reached the crystalline temperature at $0.7 \mathrm{~V}$ with $100 \mathrm{~ns}$ pulse width meanwhile the $800 \mathrm{~nm}$ channel of $\mathrm{SiC}$ can reached the crystalline temperature at $1.1 \mathrm{~V}$ with $100 \mathrm{~ns}$ pulse width. The phase transition of GST occurred when the applied voltage is $0.7 \mathrm{~V}$ at $100 \mathrm{~ns}$ pulse width for $300 \mathrm{~nm}$ channel of $\mathrm{SiC}$ and applied voltage is $1.1 \mathrm{~V}$ at $100 \mathrm{~ns}$ pulse width for $800 \mathrm{~nm}$ channel of SiC. The channel of SiC can affect the temperature of GST and phase transition of GST. The decreasing channel of SiC lead to the increase of GST temperature and the rate of phase transition of GST become faster. It can be concluded that the channel of SiC play an important role in the transformation of GST's phase and the temperature of GST.

\section{Acknowledgement}

The authors gratefully acknowledge the help of the the Institute of Research Management and Innovation (IRMI) Universiti Teknologi Mara (Uitm) Shah Alam under Research Entity Initiative (REI) (Grant No. 600-IRMI/DANA 5/3/REI (3/2017)).

\section{References}

[1] Wong H-SP, Raoux S, Kim S, Liang J, Reifenberg JP, Rajendran B, (2010) Phase Change Memory. Proc IEEE. 98(12) 2201-27.

[2] Hu Y, Feng X, Zhai J, Wen T, Lai T, Song S, (2014) Superlatticelike Ge $8 \mathrm{Sb} 92$ / Ge thin films for high speed and low power consumption phase change memory application. Scripta Materialia 93 pp. 4-7.

[3] Yin Y, Alip RI, Zhang YL, Hosaka S. (2012) Material Engineering for Low Power Consumption and Multi-Level Storage in Lateral Phase-Change Memory. Advanced Materials Research. 490 pp.3286-3290

[4] Irma R, Kobayashi R, Zhang YL. (2013) A Novel Phase-Change Memory with a Separate Heater Characterized by Constant Resistance for Multilevel Storage. Key Engineering Materials. 534 pp.136-140.

[5] RI Alip, Z Mohamad, Y Yin, S Hosaka (2014) Effect of a separate heater structure for crystallisation to enable multilevel storage phase-change memory. International Journal of Nanotechnology 11 (5-678), pp.389-395.

[6] P. Wang and Y. Chen and S. Li and S. Raju and L. Wang and L. Zhang and X. Lin and Z. Song and M. Chan (2017). Low Power Phase Change Memory With Vertical Carbon Nanotube Electrode. IEEE Journal of the Electron Devices Society 5(5). pp.362-366.

[7] T. Morikawa and K. Akita and T. Ohyanagi and M. Kitamura and M. Kinoshita and M. Tai and N. Takaura (2012). A low power phase change memory using low thermal conductive doped- 
Ge2Sb2Te 5 with nano-crystalline structure. 2012 International Electron Devices Meeting. 31.4.1-31.4.4.

[8] Lacaita a. L. (2006). Phase change memories: State-of-the-art, challenges and perspectives. Solid State Electronic. 50(1) pp.24-31.

[9] X. She and R. Datta and M. H. Todorovic and G. Mandrusiak and J Dai and T. Frangieh and P. Cioffi and B. Rowden and F. Mueller (2017). High Performance Silicon Carbide Power Block for Industry Applications. IEEE Transactions on Industry Applications. 53(4) pp.3738-3747.

[10] F. F. Wang and Z. Zhang (2016). Overview of silicon carbide technology: Device, converter, system, and application. CPSS Transactions on Power Electronics and Applications. 1(1) pp.13-32.

[11] X. She and A. Q. Huang and Ó. Lucía and B. Ozpineci (2017). Review of Silicon Carbide Power Devices and Their Applications. IEEE Transactions on Industrial Electronics. 64(10) pp.8193-8205. 